\section{FLEXIBILITY IS ESSENTIAL}

Instructional faculty should, to the extent possible, make syllabi and course plans "portable" and flexible so they can be converted from face-to-face to online or hybrid as needed. Even if your campus plans to resume fully face-to-face operations, students will get sick or need to quarantine after exposure to COVID-19, and you may be in this position yourself. If you're a parent or caregiver of a young child or children you may also find yourself at home with a sick or quarantined child. Plan for these disruptions and decide whether you'll continue class sessions synchronously, offer a remote option for sick or quarantined students, or post asynchronous content online for your students when you or they are unable to attend class in person. Pandemic teaching is at its core a lesson in flexibility with oneself and with one's students, colleagues, and family.

\section{ADOPT CHANGING TECHNIQUES}

Embrace the innovations we have made in teaching, research, and learning throughout the past eighteen months. Many of our colleagues did not know what Zoom was or how to use it before March 2020, and now they are adept at hosting meetings, sharing screens, and setting up breakout groups to run classes almost as smoothly as they do in person (give or take the occasional Wifi lag). Virtual conferences and workshops have made the exchange of ideas and research more accessible to scholars who do not have sufficient travel funding or who face visa barriers to attend in person. Virtual conferences and workshops are also far easier to attend with young children in tow, reducing the obstacles to parents' and caregivers' participation. Some conferences, as well as universities, have offered "participation grants" or compensation for technology upgrades for faculty and students needing accommodation for ADA reasons, for example. The pandemic has exposed the "digital divide" for low-income and rural students without access to high speed Internet. Faculty and universities should do their best to make the classroom accessible for everyone.

\section{KEEP AN OPEN LINE OF COMMUNICATION}

Communicate with students and colleagues early and openly. Because pandemic teaching requires so much flexibility and anticipation of contingencies, it also demands frequent, clear communication of plans and expectations. When teaching virtually in spring 2020, fall 2020, and spring 2021, students benefited from regular communication about deadlines, resources, expectations, and the professor's availability to help. To experienced faculty, these communications may feel redundant, but students in our classes articulated that they were essential to their success in virtual learning. The same need for frequent, clear communication applies to in-person classes, especially when disruptions are inevitable and even temporary changes to course modalities are likely. It is also important to communicate your own constraints, to the degree that you are willing to do so. We are upfront with our students about our role as parents and the likelihood that even run-of-the-mill childhood colds that will automatically trigger school quarantines during this fourth pandemic semester. This openness may not always be met with grace and warmth from students or colleagues (this is especially dependent upon gender and race), but by modeling our own humanity we set an important example. We also call upon department heads and campus administrators to communicate clearly about policies, options for remote work and flexible course modalities, and available resources and support systems.

The fall 2021 semester is going to be challenging and we all long for the pre-pandemic days. But in our longing we cannot ignore the realities of the world in which we currently reside, a world that demands empathy, flexibility, grace, creativity, and communication.

\title{
2021 Pi Sigma Alpha Awardees
}

\section{Best Honors Thesis}

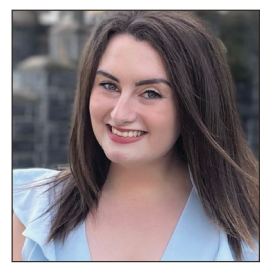

\section{Sela Dragich}

Georgetown

University, Delta Eta chapter

"The Impact of Institutions on

Access to Voting on US Reservations and Tribal Lands"

\section{Best Undergraduate Class Paper}

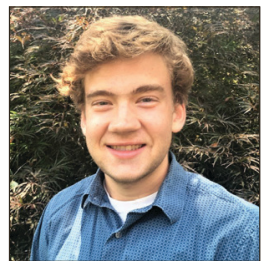

\section{Dillon Schweers}

University of Mary

Washington, Kappa Upsilon chapter

"Violence Against Journalists

in Mexico"

\section{Runners-up for Best Honors Thesis}

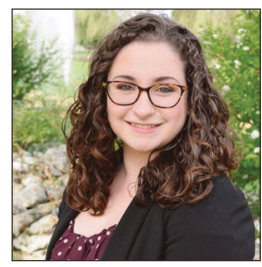

\section{Kaitlyn Fales}

Bryant University, Chi Nu chapter

"Instrumental vs. Expressive: A Study of Voter Behavioral Models Through the Lens of Identity in the 2016 Presidential Election"

\section{Runners-up for Best Undergraduate Class Paper}

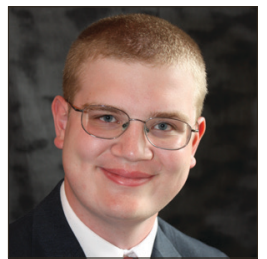




\section{Runners-up for Best Honors Thesis}

Runners-up for Best

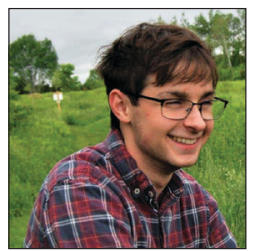

\section{Lee Hughes}

University of Vermont, Alpha Zeta Sigma chapter

"Social Capital and Disasters: a Study of Post-

Hurricane Behavior

\& Attitudes in the United States"

\section{Howard Penniman Graduate Scholarship}

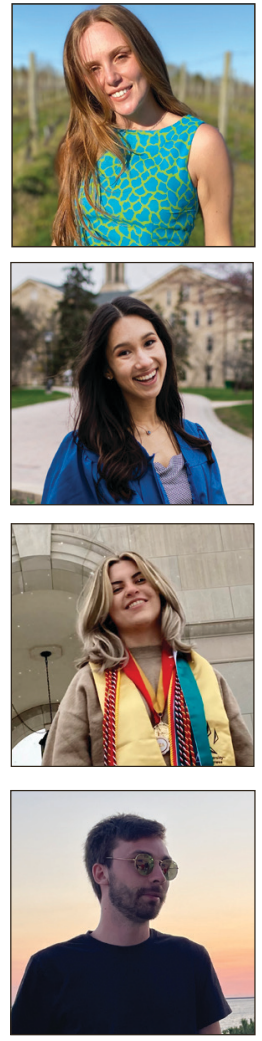

\section{Margaret Poulos}

Macalester College, Delta Chi chapter

MPP, Duke University

\section{Lyndi Tsering}

Wheaton College, Upsilon Psi chapter

MA in East Asian Studies, Walsh School of Foreign Service at Georgetown University

\section{Christina Walker}

Oakland University, Nu Omega chapter

$\mathrm{PhD}$ in Political Science, Purdue University

\section{David Westby}

Tufts University, Rho Omicron Chapter

PhD in Political Science, University of Chicago

\section{Lengle Faculty Advisor Recognition Award}

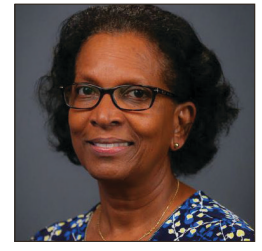

\section{Dr. Alice Jackson}

Morgan State University, Zeta Psi Chapter

\section{Best Chapter}

Undergraduate Enrollment 15,000- 25,000

Alpha Delta Beta chapter, California State University, Fresno

Sigma Mu chapter, University of Central Oklahoma

Nu Omega chapter, Oakland University

\section{Undergraduate Enrollment over 25,000}

Delta Omega chapter, Purdue University

Delta Theta chapter, Arizona State University

Epsilon Eta chapter, California State University, Fullerton

\section{Undergraduate Class Paper}

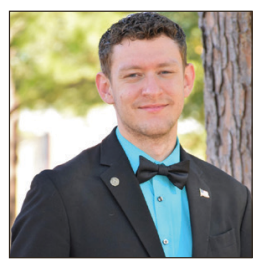

\section{Brendon Camp}

Lamar University, Zeta Lambda chapter

"Implied Consent: A Review of Judicial Process and Constitutional Law"

\section{McManus Washington Internship Scholarship}
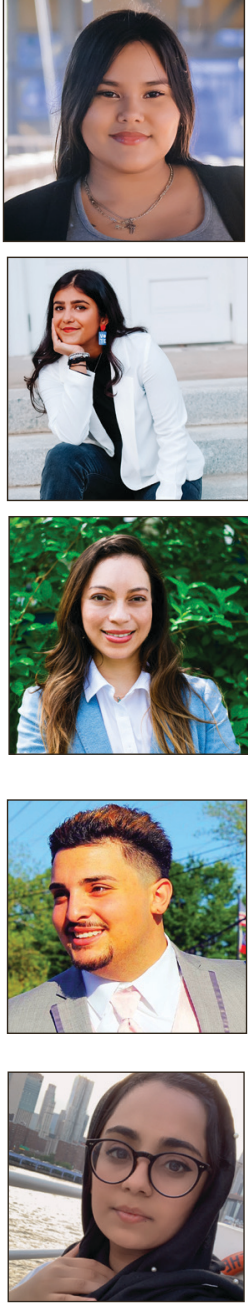

\section{Saher Shafiq}

Hofstra University, Eta Pi chapter

The Washington Center

\section{Veronica Kessler}

Smith College, Alpha Zeta Lambda chapter

Woodrow Wilson International Center for Scholars

\section{Griffin Petty}

Valdosta State University, Alpha Beta Mu chapter

Office of Representative Dina Titus

\section{Best Chapter}

Undergraduate Enrollment under 5,000 Beta Xi chapter, University of Richmond

Alpha Alpha Nu chapter, LaGrange College

Alpha Delta Omicron chapter, Dominican University of California

Undergraduate Enrollment 5,000-15,000

Tau Psi chapter, Purdue University Northwest

Alpha Theta Beta chapter, Missouri Western State University

Eta Eta chapter, New Mexico State University 